
e-ISSN 2016/Atual: 2525-7870 | e-ISSN 2015/2016: 2447-018X

\title{
A Agência Brasileiro-Argentina de Contabilidade e Controle de Materiais Nucleares: Uma Leitura Neoliberal Institucionalista
}

\author{
La Agencia Brasileño-Argentina e Contabilidad y Control de Materiales
}

Nucleares (ABACC): Una Lectura Neoliberal Institucionalista

The Brazilian-Argentine Agency for Accounting and Control of Nuclear
Materials: A Neoliberal Institutionalist Approach

Bel. Diego Felipe Barbosa Antunes ${ }^{1}$

\begin{abstract}
Resumo
A América Latina é uma região rica em arranjos institucionais responsáveis por avançar processos de integração regional. Dentro dessa vastidão, alguns casos específicos acabam perdendo-se, independentemente de seu sucesso ou fracasso. Buscando contribuir para a bibliografia que procura suprir essa deficiência, o presente trabalho tem como objetivo analisar o processo de formação e a atuação de um caso bem-sucedido de integração: a Agência Brasileiro-Argentina de Contabilidade e Controle de Materiais Nucleares (ABACC). Tal análise se propõe responder à seguinte pergunta: quais elementos explicam esse sucesso? A hipótese é a de que proposições neoliberal-institucionalistas são aptas a oferecer tal explicação. Para tal, faz-se uso da teoria Neoliberal Institucionalista para compreender de que forma essa agência contribuiu para o fim das tensões nucleares entre Brasil e Argentina no fim do século passado. O artigo se divide em três seções: na primeira, realiza-se uma discussão acerca do Neoliberalismo Institucionalista, suas propostas, críticas e choques com o Neorrealismo; em seguida, o processo histórico de formação da ABACC, bem como seus meios de atuação, é apresentado; por fim, a terceira seção realiza um esforço de leitura da atuação da agência a partir do instrumental teórico neoliberal.
\end{abstract}

Palavras-Chave: ABACC; Argentina; Brasil; integração regional; não-proliferação nuclear; Neoliberalismo Institucionalista.

\section{Resumen}

América Latina es una región rica en arreglos institucionales responsables por avance los procesos de integración regional. Dentro de esta inmensidad, algunos casos específicos terminan se perdiendo olvidados, independientemente de su éxito o fracaso. Buscando contribuir a la literatura que trata de superar esta deficiencia, este estudio tiene como objetivo analizar el proceso de formación y el funcionamiento de un caso de éxito de la integración: la Agencia Brasileño-Argentina de Contabilidad y Control de Materiales Nucleares (ABACC). Este análisis pretende dar respuesta a la siguiente pregunta: ¿Qué factores explican este éxito? La hipótesis es que las proposiciones neo-liberal-institucionalistas son capaces de ofrecer tal explicación. Para ello, se hace uso de la teoría Neoliberal Institucionalista para entender cómo la agencia contribuyó al final de las tensiones nucleares entre Brasil y Argentina a finales del siglo pasado. El artículo se divide en tres secciones: en la primera tuvo lugar una discusión sobre las propuestas y criticas Neoliberais, así como sus choques con el Neorrealismo; entonces se presenta el proceso histórico de formación de la ABACC y sus medios de acción; por último, la tercera sección presenta una lectura neoliberal de sus operaciones.

Palabras clave: ABACC; Argentina; Brasil; integración regional; non-proliferación nuclear; Neoliberalismo Institucionalista.

\footnotetext{
${ }^{1}$ Bacharel em Relações Internacionais; Universidade Federal do Rio Grande do Sul - UFRGS; Porto Alegre, Rio Grande do Sul, Brasil; diego-fba@hotmail.com.
} 

e-ISSN 2016/Atual: 2525-7870 | e-ISSN 2015/2016: 2447-018X

\begin{abstract}
Latin America is a region rich in institutional arrangements that help advancing processes of regional integration. Inside such scope some cases end up lost independently of its performance. Looking to contribute to a literature that aims to overcome this deficit, this essay aims to analyze the formation and performance of a well succeeded instance of integration: the Brazilian-Argentine Agency for Accounting and Control of Nuclear Materials (ABACC). It aims to answer the following question: what elements explain this success? It asserts as its hypothesis that neoliberal-institutionalist propositions are well fit to explain this process. Therefore, this essay makes use of Neoliberal-Institutionalist theory to understand how the agency has contributed to end tensions between Brazil and Argentina in the last decades of the XX century. The following paper divides itself in three parts: first, it discusses Neoliberal Institutionalism's propositions, critiques and clashes with Neorealism; second, it underlines ABACC's historical formation process as well as its means of proceeding; third, it presents an attempt to approach ABACC from a neoliberal perspective.
\end{abstract}

Keywords: ABACC; Argentina; Brazil; regional integration; nuclear non-proliferation; Neoliberal Institutionalism.

\title{
1. Introdução
}

Ao longo da década de 1970, Robert Keohane e Joseph Nye escreveram ostensivamente sobre importantes mudanças pelas quais passava o Sistema Internacional da época. Tratava-se de uma complexificação das relações internacionais, com novas formas de interação e novos atores para desempenhá-las se fazendo manifestos (RANA, 2015). Os autores centraram-se mais a fundo no papel das Empresas Transnacionais nesse processo, mas não negligenciaram a ascensão de outros tais como as Organizações Internacionais. De fato, a partir do fim da Segunda Guerra Mundial e do surgimento da ONU, há uma grande proliferação dessas organizações.

Um outro tipo de proliferação, a nuclear, também teve início com o fim da Segunda Guerra Mundial, quando União Soviética, Reino Unido, França e China (respectivamente nessa ordem) lograram acessar a tecnologia bélica surgida nos Estados Unidos. A partir daí, tem-se início um concerto por parte desses cinco países para impedir que outros consigam desenvolver capacidade bélica nuclear, esforço que acaba por dificultar o acesso à finalidade mais abrangente da tecnologia: a produção de energia. É com base nesse esforço que o Tratado de Não-Proliferação Nuclear (TNP) é criado em 1969, com base no qual todos os países signatários se abstêm de buscarem desenvolver ou adquirir armas nucleares.

O objeto de estudo da presente investigação se apresenta como um cruzamento desses dois processos. Brasil e Argentina dialogaram de formas separadas e, em dados momentos, mesmo conflitivas com o regime de não-proliferação nuclear criado a partir dos países do Norte. Após algumas décadas de pressões internacionais e recusas brasileiras e argentinas de adentrar esse regime, os dois países criam em 1991 uma organização internacional que une seus esforços em dialogar com o mundo acerca de questões nucleares: a Agência BrasileiroArgentina de Contabilidade e Controle de Materiais Nucleares - ABACC. 

e-ISSN 2016/Atual: 2525-7870 | e-ISSN 2015/2016: 2447-018X

A ABACC é considerada um modelo a ser seguido pelo resto do mundo. E de fato o é. Segundo Rodrigo Alvarez (2012, p. 10), a agência tornou-se referência internacional de arquitetura nuclear regional, promovendo de forma eficaz a transparência e o accountability nuclear. O autor menciona que a Enhanced Nuclear Transparency in Northeast Asia (ENTNEA) provavelmente recebeu inspiração na agência brasileiro-argentina. Também B-K Kim e David Albright (2001) trabalham a ideia de exportar o modelo da ABACC para a península coreana, afirmando que a ideia de salvaguardas binacionais seria muito benéfica para as relações entre as duas Coreias.

Mas o que explica esse relativo sucesso? Como hipótese a essa pergunta, afirma-se preliminarmente que proposições neoliberal-institucionalistas oferecem capacidade explicativa satisfatória para a mesma. Dessa forma, o problema de pesquisa é delimitado teoricamente pelo Neoliberalismo Institucionalista. No campo acadêmico das Relações Internacionais, as décadas de 1980 e 1990 marcaram a oposição desta teoria com o Neorrealismo, contenda que ficou conhecida na literatura como "Debate Neo-Neo acerca dos meios conflitivos ou cooperativos pelos quais os países interagiam.

Assim, é objetivo do presente trabalho realizar uma leitura Neoliberal acerca do processo de formação e da atuação da $\mathrm{ABACC}$, demonstrando porque o concorrente neorrealista se mostra insuficiente para entender este processo. Para tal, este artigo se dividiu em três seções: na primeira, apresenta-se o desenvolvimento da teoria Neoliberal Institucionalista, bem como seus postulados e propostas teóricas; na segunda, analisa-se o processo histórico que levou ao surgimento da $\mathrm{ABACC}$, cujas características e funções são apresentadas; por fim, na terceira seção tem-se uma tentativa de entender a agência através de um prisma neoliberal.

Percebe-se que a ABACC é avaliada positivamente por analistas e estudiosos, o que fica bem claro em qualquer relatório ou trabalho acadêmico a seu respeito. Ainda assim, é notável que tanto o processo de formação da agência quanto o seu funcionamento sejam apenas marginalmente tratados na academia brasileira, e praticamente ausentes do conhecimento civil. Levando essa deficiência em conta, este trabalho se justifica também pela necessidade de atrair mais atenção - acadêmica e geral - para um exemplo bem-sucedido de integração regional em matéria de segurança e controle nuclear.

\section{O Neoliberalismo Institucional e o Debate "Neo x Neo"}

Tal como ressalta Pedro Mendes (p. 10-11, 2010), as Relações Internacionais enquanto disciplina acadêmica surgiu e se desenvolveu através das teorias e paradigmas que foram 
sendo propostas e reformuladas. Contudo, partindo de uma perspectiva contextualista, percebe-se que tais teorias jamais surgiram descoladas do momento histórico em que estavam inseridas. Assim, pode-se dizer que as Relações Internacionais surgiram na década de 1920 em concomitância com a ascensão do Idealismo (ou Institucionalismo Liberal), corpo de ideias que se apresentou como útil e desejável ao objetivo de evitar que novos horrores como a Primeira Guerra Mundial voltassem a ocorrer. Com base em ideias liberais e institucionalistas é que se consolidou a Liga das Nações e todo o arquétipo de instituições que, ao se mostrarem impotentes diante da eclosão da Segunda Guerra Mundial, afundou junto com a teoria que lhe deu sustentação.

O novo conflito mundial e a Guerra Fria garantiram legitimidade ao ascendente Realismo e suas ideias de competição e autoajuda (self help), com um arcabouço teórico coerente para as décadas de 1950 e 1960 mas que, com a complexificação subsequente do fenômeno internacional (novos atores relevantes no Sistema Internacional, bem como novas formas de interação) acabou perdendo capacidade explicativa e abrindo espaço para o retorno do Liberalismo, na forma do Funcionalismo. De acordo com João Nogueira:

O funcionalismo e, posteriormente, o neofuncionalismo deram importantes contribuições para a pesquisa sobre o funcionamento das organizações internacionais, mas tornaram-se um alvo fácil para a crítica realista que afirma que as coalizões e o comportamento dos atores dentro dessas organizações (...) podiam refletir o peso relativo de cada um, no que se refere aos processos que tinham lugar em seu âmbito, mas não respondiam a perguntas fundamentais sobre a relevância de tais processos para as Relações Internacionais como um todo ou sobre o impacto das variáveis estudadas sobre o comportamento dos atores (NOGUEIRA, 2005, p. 23)

Ou seja, o Funcionalismo não conseguiu resgatar a tradição liberal dentro das Relações Internacionais. Quem acabou cumprindo essa função foi o Neoliberalismo Institucional. Concomitante a ele, a resposta realista veio na forma do Neorrealismo (ou Realismo Estrutural). Mas o contexto já era outro, e a partir da década de 1980 as relações internacionais já eram diversas demais para comportar apenas duas tradições teóricas. A Crise das Grandes Narrativas e a influência dos escritos de Michel Foucault e outros filósofos embasaram a ascensão da miríade de abordagens agrupadas sob a alcunha de teorias críticas ou pós-positivistas. Dessa forma, segundo Pedro Mendes, as RI atualmente se encontram diante de cinco teorias principais: Realismo, Liberalismo, Neoliberalismo Institucional (ou Neoliberalismo), Teorias Críticas, Construtivismo e Escola Inglesa.

Longe de explorar cada uma, essa brevíssima síntese serve apenas ao propósito de localizar a teoria específica com que se propõe aqui analisar a ABACC: o Neoliberalismo 
Institucional. Tal localização é necessária pela confusão que é comumente feita com termos relacionados, mas diferentes: Liberalismo, Institucionalismo Liberal e Neoliberalismo Institucional $^{2}$. O primeiro $^{3}$, segundo Monica Salomon, refere-se a uma tradição filosófica anterior ao surgimento das RI enquanto disciplina - representada pelos trabalhos de autores como Immanuel Kant, John Locke ou Adam Smith - mas que dominou os anos iniciais da disciplina. Pioneiros internacionalistas tais como J.A. Hobson, Norman Angell ou Woodrow Wilson eram defensores de ideais liberais. O Liberalismo, assim, apresenta-se como a base sobre a qual erigiram-se o Institucionalismo-Liberal e seu sucessor Neoliberal, mas não é sinônimo dos mesmos.

A corrente realista foi bem-sucedida em retirar o Liberalismo - em sua vertente Idealista - de cena, mas não terminou com ele completamente. Teorias como o Funcionalismo mantiveram o Institucionalismo-Liberal vivo para além do pós-guerra, de forma que a criação das Nações Unidas é considerada um grande feito liberal pois, como argumenta Thalles Castro (2012, p. 357), a ONU carrega consigo, desde seu surgimento, uma missão de governança democrática e paz coletiva muito convergente com as ideias de Imannuel Kant. Assim, não é de se surpreender que o liberalismo retornasse com o desgaste do Realismo durante os anos sessenta e setenta, na forma do Neoliberalismo Institucional (ou, simplesmente, Neoliberalismo).

Essa nova proposta liberal é marcada principalmente pelos trabalhos de Robert Keohane e Joseph Nye, com a Interdependência Complexa e a subsequente teoria dos Regimes Internacionais. Contudo, apesar de advir do Liberalismo e com ele partilhar muitos pressupostos, o Neoliberalismo Institucional conta com uma diferença importante em relação ao Liberalismo Institucional antecessor: diferente do primeiro, que relega grande importância à análise de elementos interiores dos Estados (natureza humana, regimes políticos, formas de governo), o Neoliberalismo adota um pressuposto dedutivo de que todos os Estados comportam-se de maneira racional e, portanto, semelhante entre si - a dimensão interna dos Estados deixa de ter relevância analítica (MENDES, 2010, p. 17). Assim que ambas as abordagens atestem a cooperação como perfeitamente possível entre os Estados, as duas diferem na forma de explicar porque tal cooperação ocorre:

\footnotetext{
${ }^{2}$ Outros nomes para essa corrente teórica são Neo-institucionalismo e Neoliberalismo.

${ }^{3}$ De acordo com Thalles Castro (2012, p. 357), o liberalismo nas Relações Internacionais “difere, substancial e formalmente, da percepção economicista que o termo porventura também possa ter".
} 
Para os liberais clássicos, a cooperação emerge quando o homem estabelece e reforma instituições, o que permite interações cooperativas e proíbe ações coercivas. Para os institucionalistas neoliberais, a cooperação emerge porque, uma vez que os atores têm interações contínuas uns com os outros, é do auto interesse de cada um cooperar. As instituições podem estar estabelecidas, afetando as possibilidades de cooperação, mas elas não garantem a cooperação (MINGST, 2003, p. 65, tradução nossa).

Percebe-se, portanto, que ao invés de chocar-se totalmente com o Realismo, o Neoliberalismo-Institucional partilha com ele os mesmos pressupostos ontológicos: Estados monolíticos, racionais e egoístas num Sistema Internacional anárquico (SALOMON, 2002, p. 6). Mas diferente do Realismo (agora reformulado por Waltz como Realismo Estrutural, ou Neorrealismo), que a partir desses pressupostos conclui que o único tipo de interação possível seria a competição, o Neoliberalismo considera que a cooperação é não só possível - por meio da atuação das instituições - como também racional (MENDES, 2010, p. 15). Além disso, apesar de admitir a centralidade dos atores estatais, o Neoliberalismo reconhece que outros atores desprovidos de soberania nacional têm peso dentro do Sistema Internacional marcadamente empresas transnacionais (MOREIRA JUNIOR, 2012, p. 459).

O Neoliberalismo Institucional tem três objetivos analíticos: explicar porque Estados cooperam; compreender de onde surge a demanda por instituições e regimes; e avaliar o papel das instituições em moldar o comportamento dos Estados (GONÇALVES, 2011, p. 2). Como teoria de cunho liberal, a abordagem também conta com as seguintes características: entende que as Organizações Internacionais normatizam a conduta externa dos Estados; faz da boa-fé e da transparência entre Estados algo desejável; e defende a multilateralidade nas decisões interestatais (CASTRO, 2012, p. 355).

Como dito, o Neoliberalismo partilha com o Neorrealismo a ideia de anarquia, considerando que as incertezas geradas por essa situação anárquica geram um custo muito alto de transações entre os Estados, e adviria disso a propensão ao conflito. Nesse sentido, as instituições alterariam as estratégias dos atores estatais ao modificar esses custos de maneira positiva (MAIA, 2011, p. 11). Assim, é tarefa de uma instituição internacional aumentar o quão possível os custos de um comportamento egoísta e autocentrado que enfraqueça os interesses da coletividade internacional (SANTOS, 2006, p. 24).

O debate entre Neoliberalismo e Neorrealismo ("neo-neo") predominou na literatura de RI durante as décadas de 1980 e 1990 . Além da supracitada questão das consequências da anarquia sobre os Estados (competição ou cooperação), tal debate também se centrou na questão dos ganhos absolutos e ganhos relativos. Os primeiros, defendidos pelos neoliberais, referem-se aos ganhos almejados por um Estado através da cooperação com outro Estados. 
Por essa ótica, os Estados pouco se importariam com os ganhos obtidos pelo parceiro, visto que sua atenção reside no absoluto de seus próprios ganhos. Os neorrealistas condenam essa visão pois, sob a lógica do jogo de soma zero, enxergam os ganhos em termos relativos. Assim, se a cooperação beneficia um ator, esse ganho deve ser subtraído pelo ganho do parceiro - caso essa subtração resulte num valor negativo, a cooperação é irracional. Portanto, para os neorrealistas, mais seguro é o caminho da competição, pela qual os ganhos são unilaterais (SARFATI, 2005, p. 177).

Para os neoliberais, por meio da ingerência institucional torna-se cada vez mais racional afastar-se da competição e buscar a cooperação com outros atores. Essa cooperação é incentivada pelas instituições de três formas (MENDES, p. 15, 2010). Primeiro, pela extensão do horizonte temporal, uma vez que como fórum de diálogo as instituições permitem que as interações entre os Estados possam ser feitas diversas vezes, numa lógica de jogos repetidos. Assim, a postura estatal de entrar para o "tudo ou nada" deixa de ser coerente com interações regulares e periódicas. Uma derrota, dentro de uma Organização Internacional, é sempre parcial por ser circunstancial, nunca absoluta. Além disso, uma vez que os Estados tenham de interagir diversas vezes, torna-se altamente importante conservar uma reputação positiva de cumpridor de compromissos, com vistas a afastar desconfianças que atrapalhem interações futuras.

Segundo, as instituições diminuem uma das principais causas de desacordo e competição entre os Estados: a incerteza. O dilema do prisioneiro, pressuposto caro ao Realismo, só tem sentido quando os prisioneiros não têm conhecimento das intenções um do outro - ou seja, não detém informações completas. Analogamente, a função de informar os Estados é desempenhada pelas instituições. O mero cumprimento ou descumprimento de regras internacionais já é um indicativo bastante visível da postura de um Estado. Terceiro, por fim, aumenta-se a eficiência na relação entre os Estados, por dois motivos: sendo um fórum de diálogo permanente, as instituições dispensam a necessidade de trabalhosos arranjos ad hoc surgirem sempre que um problema se faz manifesto. Além disso, esse mesmo caráter permanente das instituições faz com que elas se afirmem como "pontos focais", pois uma vez consolidada, a instituição arroga para si o tratamento de qualquer tipo de questão que surja dentro de sua jurisdição. Resulta disso uma maior agilidade e eficiência no tratamento de problemas e questões internacionais, decaindo as chances de desinteligência entre os Estados.

Contudo, para além de compreender os argumentos neoliberais acerca do modo como as instituições promovem a cooperação, faz-se necessário compreender também o que esses autores entendem por instituições. De acordo com Robert Keohane (1989, p. 286), uma 
instituição é um arranjo específico construído pelos indivíduos, de forma formal ou informal. Pedro Mendes (2010, p. 5) as exemplifica como sendo "regras, normas, práticas e procedimentos decisórios" que direcionam e influenciam as expectativas dos Estados, ajudando a diminuir a incerteza entre os mesmos.

Uma das formas mais óbvias de instituições são as Organizações Internacionais. A atuação contínua das instituições incentiva, segundo Demetrius Pereira e Rafael Rocha (2015, p. 442) a supranacionalidade, ou seja, a "progressiva transferência de competências dos Estados para as instituições internacionais. "Tal supranacionalidade é comumente identificada com o fortalecimento de organizações onde essas soberanias são depositadas - a Organização das Nações Unidas ou o Mercosul, por exemplo. Tais organizações têm grande impacto nas relações entre os Estados pois, além de favorecer a consolidação permanente das negociações interestatais, elas também permitem a democratização das decisões internacionais ao possibilitar a decisão por maioria. Além disso, tais organizações também são capazes de desenvolver procedimentos de controle de aplicações de regras, além da formação de regimes internacionais. Por fim, as Organizações Internacionais também propiciam a construção de valores, como a promoção dos Direitos Humanos ou a incorporação de novos atores na Comunidade Internacional.

Mas não apenas instituições visíveis em prédios ou locais concretos. As atuais definições neoliberais de instituição também congregam elementos mais intangíveis. A busca pela paz, por exemplo, deve ser entendida como um modo de conduzir as relações internacionais que passem pelo respeito às regras westfalianas (instituições) tais como a nãoingerência, a igualdade jurídica ou o respeito a diversidade religiosa e política (PEREIRA; RAFAEL, 2015, p. 440). Ou seja, quando se fala em instituições, deve-se ter em mente, para além de Organizações Internacionais, outros elementos de igual peso e relevância sobre o comportamento dos Estados. Percebe-se, portanto, que o movimento do Liberalismo clássico (Idealismo) até o Neoliberalismo Institucional evidencia uma abertura do conceito de "instituição", de uma noção puramente formal e burocrática para o abrangente conceito de regimes - princípios, normas, regras e procedimentos, ou seja, um "guarda-chuva" de instituições formais e informais.

\section{ABACC: histórico e características de uma experiência bem-sucedida}

\subsection{Processo histórico}

Após o surgimento da tecnologia nuclear no fim da Segunda Guerra Mundial, houve um esforço generalizado por parte de diversos países que, cada um a seus meios, buscaram ter 

e-ISSN 2016/Atual: 2525-7870 | e-ISSN 2015/2016: 2447-018X

acesso à mesma. Durante a maior parte da segunda metade do século XX, foram três os países latino-americanos que integraram esse esforço: Cuba, Brasil e Argentina. O primeiro o tentou por meio do fornecimento direto soviético - ação que resultou na chamada "Crise dos Mísseis" em 1961 -, os outros dois seguiram um caminho mais autônomo de busca de desenvolvimento nacional da tecnologia (ALVAREZ, 2012, p. 6).

Ambos começaram já na década de 1950 esse esforço, atraídos pelos benefícios do emprego da energia nuclear em cadeias produtivas. Ainda assim, tanto brasileiros quanto argentinos tinham ciência de que uma tecnologia tão sensível não lhes seria entregue como no caso cubano - este beneficiado pela disputa geopolítica da Guerra Fria. Vem disso a opção pelo desenvolvimento autônomo. Assim, em 1974, a Argentina conclui a construção de seu primeiro reator nuclear, o Atucha I. O Brasil fez o mesmo sete anos depois, em 1981, com a construção do Angra I (ORSTEIN, 2011, p.5).

Mas para além dos benefícios da energia nuclear, os dois maiores países da América do Sul também atentavam para o equilíbrio de poder no pós-guerra, e a posição que ambos almejavam alcançar. Parte disso, portanto, o fato de os dois países começarem desde o início a flertar com o a dimensão militar de seus programas nucleares, fixando o desenvolvimento de Armas de Destruição em Massa (ADMs) como objetivo secreto - apesar de ambos os governos negarem tal fato. Dada a simultaneidade de ambos os processos, resultou uma espécie de rivalidade mútua entre os dois países no campo nuclear (ALVAREZ, 2012, p. 6) rivalidade que se encaixou numa mais ampla, por hegemonia regional.

De acordo com Sara Kutchesfahani (2010, p. 3), três motivos se cruzaram para alimentar a desconfiança que se instalou entre Brasil e Argentina durante as décadas de 1950 aos anos 1970: primeiro, tratavam-se de rivais históricos, sob domínio de governos militares que davam grande ênfase à questões geopolíticas; segundo, já nesse período encontravam-se avançados no domínio de boa parte do ciclo nuclear, o que tornava a hipótese de desenvolvimento de artefatos bélicos minimamente plausível; e terceiro, a resistência de Brasil e Argentina em aderir ao regime de não-proliferação nuclear vigente - Nuclear Supliers Group $^{4}$, Tratado de Tlatelolco 5 , Tratado de Não-proliferação Nuclear (TNP), além de negarem inspeções da Agência Nacional de Energia (AIEA). Mais do que a desconfiança

\footnotetext{
${ }^{4}$ Grupo de Fornecedores Nucleares (em tradução livre), o qual busca prevenir a proliferação nuclear por meio do controle de exportação de materiais nucleares.

${ }^{5}$ Também conhecido como Tratado de Proscrição de Armas Nucleares na América Latina e Caribe, vigente desde 1969. Estipulou a desnuclearização total da América Latina e Caribe, criando a primeira Zona Livre de Armas Nucleares (Nuclear Weapons Free Zone, ou NWFZ) do mundo em local habitado (antes dele já vigoravam NWFZ's no espaço sideral e na Antártida).
} 

e-ISSN 2016/Atual: 2525-7870 | e-ISSN 2015/2016: 2447-018X

mútua, essa situação gerava também a desconfiança da Comunidade Internacional sobre os dois.

Essa situação começou a se alterar a partir do fim da década de 1970, por iniciativa dos dois governos. Em 1977 tem-se a primeira declaração conjunta entre dos ministros de relações exteriores brasileiro e argentino, onde se afirmava a importância da cooperação nuclear bem como exortava-se pelo intercâmbio entre as comissões nacionais de energia nuclear. Em 1980 o processo tem continuidade com o Acordo de Cooperação para o Desenvolvimento e Aplicação dos Usos Pacíficos da Energia Nuclear, onde buscava-se estabelecer meios de tornar transparente os programas dos dois países (OLIVEIRA; CANTO, 2013, p. 4).

O processo de construção de confiança ganhou grande ímpeto com o início das declarações presidenciais conjuntas. A primeira foi a Declaração de Iguaçu, de 29 de novembro de 1985, onde os presidentes José Sarney e Raúl Alfonsin afirmavam a tecnologia nuclear como vital para o desenvolvimento nacional. No dia seguinte, os dois presidentes emitiram a Declaração Conjunta sobre Política Nuclear, anunciando a criação de um grupo de trabalho misto que analisasse os meios de garantir o caráter pacífico de seus programas. Em 1987, tem-se a Declaração de Viena, na ocasião da visita de Sarney a algumas instalações nucleares argentinas - nela era discutida a possibilidade de integração produtiva das indústrias nucleares.

No ano seguinte, Raúl Alfonsin visita o Centro Experimental de Aramar, emitindo em conjunto com José Sarney a Declaração de Iperó, onde clamou-se pela ampliação dos esforços existentes e decidiu-se por fazer do grupo de trabalho anteriormente criado um Comitê Permanente sobre Política Nuclear. Em 6 de julho de 1990, tem-se o Comunicado de Buenos Aires, pelo qual os presidentes Fernando Henrique Cardoso e Carlos Menem reafirmam a importância de seus programas nucleares para o desenvolvimento de ambos os países.

Em 29 de novembro daquele ano, os dois emitem a Declaração sobre uma Política Nuclear Comum, onde se aprova a criação do Sistema Comum de Contabilidade e Controle de Materiais Nucleares (SCCC), a base final sob a qual a ABACC viria a ser criada. Assim, 18 de julho do ano seguinte, tem-se o Acordo de Guadalajara para o Uso Exclusivamente Pacífico da Energia Nuclear, onde fica acordado a criação da ABACC e o uso pela mesma do SCCC. Por fim, em 13 de dezembro de 1991, firma-se o Acordo entre Brasil, Argentina, a AIEA e a ABACC (ou Acordo Quadripartite) onde a cooperação entre os quatro atores é regularizada (OLIVEIRA; DO CANTO, 2013, p. 4-5). 
Trata-se de um processo que levou onze anos para passar de meras iniciativas e intenções cooperativas para um robusto corpo institucionalizado, contabilizando doze acordos e quatorze declarações (ALVAREZ, 2012, p. 9). Apesar dos números e do longo espaço de tempo, Antônio Oliveira e Odilon do Canto argumentam que havia uma coerência entre todos esses acordos e declarações, de forma a ser possível discernir seis princípios implícitos em todos eles:

1. A reafirmação do caráter exclusivamente pacífico do uso da energia nuclear no Brasil e Argentina. 2. O fortalecimento e fomento da confiança mútua (projetos conjuntos, intercâmbio de informação, visitas recíprocas). 3. A promoção do uso pacífico da energia nuclear para o benefício dos povos de ambas as nações. 4. 0 potencial para acordos de cooperação com outros países de América Latina. 5. S política exterior comum na área nuclear. 6 . O fomento dos conceitos de paz e segurança regionais (OLIVEIRA; DO CANTO, 2013, p. 4).

\subsection{Função e características}

A ABACC é uma Organização Internacional inovadora: para o mundo, por tratar-se da única organização de salvaguardas nucleares binacional; para ambos Brasil e Argentina, por ser a primeira organização binacional entre dos dois países. Sua função é a de verificar e evidenciar o uso pacífico de materiais nucleares que possam ser desviados do propósito de produção de energia e redirecionados para a produção de armas nucleares (OLIVEIRA; CANTO, 2013, p. 6). Em razão disso, a ABACC reveste-se de importância ímpar quando se leva em conta que seus dois Estados-membros são os dois países mais avançados em tecnologia nuclear da América Latina - ou seja, cujo peso é crucial para o funcionamento do regime de não-proliferação na região (ALVAREZ, 2012, p. 2).

Uma característica positiva da agência é o fato de ela ter sido criada por Brasil e Argentina para que vigiassem a si mesmos. Ou seja, diferente do Tratado de Não-proliferação, não há, no caso da $\mathrm{ABACC}$, ressentimento ou desconfiança para com a sujeição a um instrumento de controle de salvaguardas criado e imposto externamente. Trata-se da lógica de "vizinhos vigiam vizinhos" (ORSTEIN, 2011, p. 5). Reforço a essa ideia é a regra de que os funcionários da $\mathrm{ABACC}$, apesar de provenientes dos dois países, não respondem a nenhum dos dois, sendo considerados funcionários internacionais (REDICK, 1994, p. 1).

O surgimento da $\mathrm{ABACC}$ é responsável por um importante processo de uniformização dos programas nucleares brasileiro e argentino: de requisitos e procedimentos de salvaguardas, de regras de controle de materiais nucleares, e de tipos de verificação. Além da uniformização, a agência também se caracteriza por ser edificada sobre três pilares: salvaguardas, capacitação de técnicos e inspetores e cooperação técnica com organizações 
internacionais do ramo. Por fim, as funções operacionais da ABACC são executadas de acordo com os parâmetros ditados pelo SCCC, no tocante ao licenciamento de abertura de novas instalações nucleares no território dos dois países ou sob jurisdição dos mesmos; na aplicação de inspeções por parte de um país ao outro; e na aplicação de inspeções por parte da ABACC em países terceiros (OLIVEIRA, DO CANTO, 2013, p. 13; ALVAREZ, 2012, p. 9).

\subsection{Desenho institucional}

A ABACC é constituída por oito setores, cada qual com funções bem delimitadas. A Comissão é a unidade máxima, responsável por decisões sobre a própria gestão da agência tais como a nomeação dos oficiais de alto nível a comporem a organização, bem como a seleção de inspetores a realizar as vistorias. Já a secretaria engloba o pessoal técnico encarregado de executar atividades necessárias para a aplicação do SCCC. O Setor de Planejamento e Avaliação é quem estipula os critérios de avaliação para as inspeções, de forma a garantir as salvaguardas.

O Setor de Contabilidade de Materiais Nucleares analisa a contabilidade desses materiais fornecidas pela AIEA, pelas autoridades nacionais e pelos inspetores da ABACC. É aqui que se verifica possíveis discrepâncias nas informações, bem como se dissemina as informações para ambos os países. O Setor de Apoio Técnico, por sua vez, é responsável pela compra e registro de equipamentos comprados pelas instalações nucleares de ambos os países, garantindo seu uso para fins pacíficos. Também busca promover o desenvolvimento de tecnologias autônomas. A agência também conta com um Setor de Relações Institucionais, cujo objetivo é fazer a comunicação entre a ABACC e a sociedade civil, bem como com outras organizações do ramo. Nesse setor também se desenvolvem revistas e informativos sobre a Agência, tais como o ABACC News. Por fim, tem-se o Setor Administrativo e Financeiro, cujas atribuições envolvem o gerenciamento dos recursos financeiros da agência.

Mas em termos de execução, é o Setor Operacional quem põe em prática os meios de concretizar os objetivos gerais da agência. Tal setor engloba o pessoal que vai a campo realizar as inspeções nas instalações nucleares de ambos os países. A preocupação com a transparência e com a boa-fé tem reflexos na forma como esse setor é configurado. Por exemplo, em 2013 registrava-se cerca de 100 inspetores atuantes, sendo que a proporção de inspetores argentinos e brasileiros era bastante equilibrada. Além disso, as inspeções em um país são realizadas por inspetores do outro país, e vice-versa.

Sobre as inspeções, é pertinente ressaltar que ela pode ser de dois tipos: a Verificação de Inventário Físico, que é feita de uma vez, com resultados estáticos; e a Inspeções Interinas, 
feitas várias vezes para acompanhar a evolução do material nuclear e da instalação sob observação. As inspeções também se dividem entre Anunciadas e Não-anunciadas - ou seja, a possibilidade de uma inspeção surpresa ocorrer é real, conferindo a exigência de ainda mais transparência por parte dos dois países. Por fim, é o setor que capacita os inspetores e avalia seu desempenho (OLIVEIRA; DO CANTO, 2013, p. 7-13).

\subsection{Cooperação com outras organizações e países}

Um aspecto importante da atuação da ABACC é sua disposição a cooperar com outros atores inseridos no regime de não-proliferação. Trata-se de uma necessidade, visto que uma agência binacional que busque legitimar o uso de energia nuclear de seus dois países não pode se preocupar apenas com as percepções de ameaça ou confiança um do outro, mas também com as percepções do resto dos países e organizações da Sociedade Internacional. Essa preocupação esteve presente desde sempre. Alguns meses após o surgimento da agência, é celebrado entre Brasil, Argentina, a ABACC e a AIEA o Acordo Quadripartite. Inovador em seu conceito, envolve Estados e Organizações Internacionais (OLIVEIRA, DO CANTO; 2013, p, 5).

Pelo acordo, inspeções da AIEA passavam a ser autorizadas nas instalações brasileiras e argentinas, a fim de verificar se as inspeções da ABACC realizadas sob o protocolo do SCCC estavam de acordo. Esse mecanismo passa a ser possível, mas não é automático ocorre somente quando um dos dois países desconfia de anomalias nas inspeções, desejando uma segunda inspeção pela AIEA. Excluindo essa situação, a ABACC permanece como autoridade máxima nos dois países, sendo responsável pelas inspeções (REDICK, 1994, p. 1). Ainda assim, a pressão internacional para que os dois países aceitassem inspeções da AIEA esvanecem-se, sob os termos oferecidos por Brasil e Argentina.

Além da AIEA, países como Estados Unidos, França ou Coreia do Sul já assinaram acordos de cooperação com a ABACC envolvendo iniciativas de formação de inspetores ou definição de salvaguardas. Por fim, a agência tem empreendido um esforço de aproximação com sua correspondente europeia, a EUROATOM. Em 1999 foi assinado o primeiro Acordo de Cooperação de Pesquisa, Desenvolvimento e Treinamento de Salvaguardas, o qual garantia cursos de capacitação para os inspetores brasileiros, bem como intercâmbios técnicos. Mais recentemente, em 2012, foi aprovado o projeto "Strenghtening the safeguards capabilities of $A B A C C$ ", dentro do escopo desse acordo (GONÇALVES et al, 2015). 

e-ISSN 2016/Atual: 2525-7870 | e-ISSN 2015/2016: 2447-018X

\title{
4. Cooperação, informação e ganhos absolutos: uma leitura Neoliberal
}

Há um certo consenso entre análises feitas sobre a ABACC acerca de seu sucesso perante os objetivos fixados. Falando sobre a agência, o Secretário da mesma, Odilon Marcuzzo do Canto, afirma:

\begin{abstract}
A história tem demonstrado que, sem dúvida, o melhor caminho para garantir a segurança e o progresso para a humanidade é promovendo o entendimento e a cooperação entre as nações. Brasil e Argentina tem orgulho de sua história, construída na base de um entendimento comum, no qual o consenso tem muito mais destaque do que eventuais disputas pontuais (DO CANTO, 2015, p. 1).
\end{abstract}

De fato, a ABACC representa uma etapa bem-sucedida nas relações Brasil-Argentina que direcionou os dois países rumo a cooperação, antes mesmo de o Mercosul existir. Um fator que ajuda a entender porque a $\mathrm{ABACC}$ é vista com bons olhos e porque os dois países cooperam com ela é justamente a desconfiança que se tinha com mecanismos externos de controle, tais como o TNP. Diferente deste, a agência não foi imposta de fora, mas planejada e adotada de dentro.

Deve-se ter esse aspecto em mente para entender porque trata-se de um exemplo de institucionalização positiva de relações interestatais. De fato, pode-se dizer que a dimensão nuclear das relações internacionais é extremamente sensível, mas que justamente nessa dimensão a ABACC produziu efeitos significativos. Alguns estudos afirmam que foi a redemocratização que impeliu brasileiros e argentinos a desistirem da bomba nuclear, mas como visto as iniciativas de aproximação entre os dois países começaram antes, no início da década de 1980. Além disso, mesmo sob rivalidade, já nos anos sessenta e setenta haviam esboços de cooperação, com Brasil e Argentina adotando posições comuns acerca da negociação do Tratado de Tlatelolco ou rejeitando a assinatura do TNP (KUTCHESFAHANI, 2010, p. 4-8).

Com a entrada da ABACC nas negociações o enfoque dos dois mudou, da arma nuclear para a energia nuclear. Esta, cada vez mais restrita internacionalmente, tornou-se mais viável com a adoção de um mecanismo de salvaguardas que, no entanto, não era o impositivo e discriminador TNP (OLIVEIRA; DO CANTO, 2013, p. 6-7). Ainda assim, é importante frisar que o contexto de aproximação não se resumiu à dimensão nuclear. A resolução de problemas pontuais concernentes ao Rio da Prata e o retorno de governos civis ajudou a construir um quadro menos conflitivo e mais construtivo para os dois países (REDDICK, 1995, p. 6). 
Uma leitura neoliberal acerca desse processo revela alguns pontos interessantes. A $\mathrm{ABACC}$ demonstra que, ao mesmo tempo em que cederam às pressões internacionais e desistiram de programas nucleares bélicos, Brasil e Argentina posicionaram-se do lado neoliberal no debate neo-neo ao adotarem a lógica de ganhos absolutos. De fato, hoje Brasil e Argentina são os dois países mais avançados da América Latina em termos de energia nuclear, algo possibilitado, como mostrou-se, graças à ABACC. Caso tivessem agido pela lógica dos ganhos relativos, ambos os países buscariam um meio de seguir seus objetivos sem que isso fortalecesse o vizinho. A agência não existiria, e o clima de tensão não seria suprimido.

Outro aspecto que direciona esse processo no sentido neoliberal é a questão da confiança, que foi paulatinamente substituindo a desconfiança para que a agência se tornasse realidade. Em outras palavras, a propensão à competição (neorrealismo) foi sendo minada por uma disposição à cooperação (neoliberalismo). Além disso, a postura dos dois países também indica uma posição neoliberal, apesar de ser um ponto partilhado com o neorrelismo. Como lembra Roberto Orstein (2011, p. 5-6), a opção pela cooperação tem em sua base tanto a desconfiança que ambos Brasil e Argentina recebiam por parte do resto do mundo, quanto à noção de que juntos os dois teriam mais chances de alcançar a tecnologia nuclear para a produção de energia. Tratou-se, portanto, de um cálculo de custo/benefício, onde a resolução da rivalidade se mostrou mais vantajosa para o alcance dos objetivos. Esse é um postulado neoliberal: a ideia de que os Estados são racionais em suas escolhas não significa automaticamente que eles entrarão em conflito, pois racionalidade não é sinônimo de competição.

Essa lógica de construção de confiança e superação da rivalidade para a consolidação de uma organização internacional que institucionalize a cooperação distingue a ABACC dos modelos liberais anteriores ao Neoliberalismo Institucional. O Idealismo, por exemplo, pregaria a ideia inversa de que os Estados precisariam de normas e instituições consolidadas para, a partir delas, ser possível construir a confiança e a cooperação entre os Estados - era a lógica por trás da construção da Liga das Nações. No caso da ABACC, a instituição foi precedida por um processo político (OLIVEIRA, DO CANTO, 2013, p. 3). Essa ordem também se choca com o que pressupõe outra abordagem liberal, o Funcionalismo, segundo o qual a integração regional ocorre por vias de transbordamento (spill-over), ou seja, pelos benefícios técnicos e operacionais que uma organização venha a apresentar motivando a iniciativa política. 
Resgatando propostas neoliberais apresentadas no primeiro capítulo deste trabalho, evidencia-se o poder explicativo que tal teoria tem sobre o objeto de estudo aqui tratado. Os três enfoques de análise apresentados por Gonçalves (2011, p. 2) são perfeitamente atendidos: explicar porque os Estados cooperam - no caso, Brasil e Argentina cooperaram para alcançarem o domínio da energia nuclear -, compreender de onde surge a demanda por instituições e regimes - da necessidade de consolidar a confiança construída previamente - e avaliar o papel das instituições em moldar o comportamento dos Estados - da rivalidade para a aproximação.

Esse último ponto fica mais evidente ao se considerar a questão da informação. $\mathrm{O}$ protocolo da ABACC para a execução de salvaguardas, o SCCC, é responsável por gerar informes contábeis e qualitativos acerca do que se produz e de como se produz em termos de energia nuclear nos dois países. Essa função, possibilitada pelas inspeções e desempenhada pelo Setor de Relações Institucionais, promove a disseminação de informações que, segundo a teoria, diminui a incerteza, quebrando a lógica do "Dilema do Prisioneiro" e, portanto, invalidando o postulado realista da competição inevitável.

\section{Conclusões}

Posicionar a ABACC em um dos dois lados do Debate Neo-Neo não se apresenta como uma tarefa difícil, visto que a convergência desta com o Neoliberalismo se faz manifesta em vários pontos. A própria criação da agência e a consequente desistência de obtenção da arma nuclear já se choca com a ideia neorrealista de Estados racionais que buscam o poder como forma de sobreviver sob uma anarquia competitiva. Uma leitura neoliberal revela que, ainda que os Estados sejam de fato racionais, não significa que eles tenham de competir. O cálculo custo/benefício realizado por Brasil e Argentina, de acordo com tal leitura, teria indicado o caminho da abstenção nuclear bélica e a cooperação nuclear civil com o vizinho como sendo o caminho mais racional a ser tomado.

A construção prévia da confiança, a disseminação de informações, a composição equilibrada de argentinos e brasileiros dentro da agência. Tudo trabalha a favor da cooperação, num arranjo institucional aclamado nacional e internacionalmente. A ABACC muito provavelmente foi um importante reforço ao processo mais geral de aproximação entre Brasil e Argentina - processo que culminou na formação do Mercosul. Ainda assim, é notável que uma agência de tamanha importância e eficiência passe batido pela atenção do público acadêmico e geral. O presente trabalho buscou, de certa forma, ajudar a preencher essa lacuna. 

e-ISSN 2016/Atual: 2525-7870 | e-ISSN 2015/2016: 2447-018X

\section{Referências}

ALVAREZ, Rodrigo. Regional approaches to nuclear security and transparency: the example of Argentina and Brazil. Nuclear Security Governance Experts Group, 2012. Disponível em: http://www.nsgeg.org/Regional\%20Approaches\%20to\%20Nuclear\%20Security\%20and\%20T ransparency-The\%20Example\%20of\%20Argentina\%20and\%20Brazil.pdf. Acesso em: 02 agosto 2016.

CASTRO; Thalles. Teoria das Relações Internacionais. Brasília: FUNAG, 2012.

DO CANTO, Odillon. Discurso apresentado na Conferência de Revisão do TNP 2015. Nova York, mai. 2015. Disponível em: http://www.abacc.org.br/wpcontent/uploads/2015/05/Discurso-TNP-2015-PORT.pdf. Acesso em 04 set. 2016.

GONÇALVES, Pascoal. Jogos ocultos e potências médias: um estudo da atuação brasileira na OMC. Campinas: Universidade Estadual de Campinas, 2011.

GONÇALVES, João; LITTMAN, François; SEQUEIRA, Vitor; SIRONI, Marco; ANDERSEN, Martin; MACHADO, Luís, PEIXOTO, Orpet; ALMEIDA, Silvio de; MORENO, Sónia. EU-ABACC Cooperation: Strenghtening Safeguards Capabilities. Proceedings of 37th ESARDA Symposium on Safeguards and Nuclear Non-Proliferation. Reino Unido, mai. 2015. Disponível em: http://www.abacc.org.br/wpcontent/uploads/2015/09/EU-ABACC-Cooperation-Manchester-2015.pdf. Acesso em: 21 setembro 2016.

KEOHANE, Robert. International Institutions: Two Approaches. In: International Institutions and State Power: Essays in International Relations. Estados Unidos: Westview Press, 1989.

KIM, B-K; ALBRIGHT, David. Wrap-up Session Summary: main themes and proposals. In: HIGGINS, Holly (ed). Building nuclear confidence on the Korean Peninsula, jul. 2001. Disponível em: http://isis-online.org/uploads/conferences/documents/wrapup.pdf. Acesso em: 04 de agosto de 2016.

KUTCHESFAHANI, Sara. Who Shapes the Politics of the Bomb? The Role of Epistemic Communities in Creating Non-Proliferation Policies. Working Paper WP, n. 3, dez. 2010.

MAIA, Cibelle. Adoção internacional: alternativa viável ou exportação de problemas? Uma interpretação do caso do Haiti no Pós-terremoto. Revista Acadêmica de Relações Internacionais, Florianópolis, v. 1, n. 2, p. 6-50, nov./fev. 2011.

MENDES, Pedro. A invenção das Relações Internacionais como Ciência Social: uma introdução a Ciência e a Política das RI. Centro de Estudos da População, Economia e Sociedade, 2010. Disponível em: http://www.cepese.pt/portal/pt/investigacao/workingpapers/relacoes-externas-de-portugal/a-invencao-das-relacoes-internacionais-como-cienciasocial-uma-introducao-a-ciencia-e-a-politica-das-ri-

2217/A\%20Invencao\%20das\%20Relacoes\%20Internacionais\%20como\%20ciencia\%20social. pdf. Aceso em 11 agosto 2016.

MINGST, Karen. Essentials of International Relations. 2 ed. Nova York: W. W. Norton, 2003. 
MOREIRA JUNIOR, Hermes. Contestando a "Ciência Social Norte-Americana": Críticas à postura conservadora das teorias do mainstream das Relações Internacionais. Brazilian Journal of International Relations, Marília, v. 1, n. 3, p. 449-480, 2012.

NOGUEIRA, João. Teoria das Relações Internacionais: correntes e debates. Rio de Janeiro: Campus, 2005.

OLIVEIRA, Antonio; DO CANTO, Odilon. ABACC, um ejemplo de integración y transparencia. IX Latin American IRPA Regional Congress on Radiation Protecion and Safety, Rio de Janeiro, 2013.

ORSTEIN, Roberto. ABACC: 20 años de exitosa existencia. CNEA, a. 11, n. 43-44, p. 5-6, jul./dez. 2011.

PEREIRA, Demétrius; ROCHA, Rafael. Segurança na União Europeia e UNASUL: entre o institucionalismo e o cosmopolitismo. Conjuntura Global, v. 4, n. 3, p. 438-456, set./dez. 2015.

RANA, Waheeda. Theory of Complex Interdepence: A comparative analysis of Realist and Liberal Thoughts. International Journal of Business and Social Science, n. 2, v. 6, fev. 2015.

REDDICK, John. Nuclear Illusions: Argentina and Brazil. Occasional Paper, Estados Unidos, n. 25, 1995.

SALOMÓN, Mónica. La teoría de las relaciones internacionales en los albores del siglo XXI: diálogo, disidencia, aproximaciones. Revista Electrónica de Estudios Internacionales, n. 4, p. $1-59,2002$.

SANTOS, Suelma Rosa dos. Estudo comparado acerca da atuação do Brasil e da Índia na Organização Mundial de Comércio de Seattle a Cancún. Brasília, Universidade de Brasília, 2006.

SARFATI, Gilberto. Teoria de Relações Internacionais. São Paulo: Saraiva, 2005. 